\title{
Territorial differentiation of physiotherapy practices in Poland
}

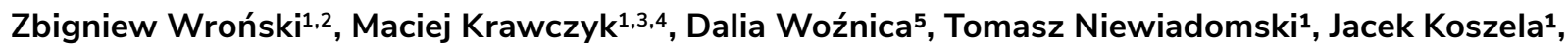 \\ Ernest Wiśniewski ${ }^{1}$, Artur Koper ${ }^{1}$, Witold Śmigielski ${ }^{6}$, Paweł Adamkiewicz $^{1}$ \\ ${ }^{1}$ Presidium of the Polish Chamber of Physiotherapists, Poland \\ 2Medical University, Warsaw, Poland \\ ${ }^{3}$ Institute of Psychiatry and Neurology, Warsaw, Poland \\ ${ }^{4}$ Faculty of Rehabilitation, Józef Pilsudski University of Physical Education, Warsaw, Poland \\ ${ }^{5}$ Department of International Cooperation, Polish Chamber of Physiotherapists, Poland \\ ${ }^{6}$ Department of Statistics and Analysis, Polish Chamber of Physiotherapists, Poland
}

Correspondence to: Zbigniew Wroński, zbigniew.wronski@kif.info.pl

DOI: https://doi.org/10.5114/for.2021.106950

Received: 07.05.2021 Reviewed: 13.05.2021 Accepted: 13.05.2021

\begin{abstract}
Background: Probably due to an oversight in the preparation phase of the legislative process, the Act on the Profession of Physiotherapy limited the possibility of conducting business activity only to medical entities. Separate regulations were introduced to allow physiotherapists to work as individual and group practitioners. Now it seems appropriate to assess how physiotherapy practices are structured in Poland.
\end{abstract}

Aims: This study aimed to perform a quantitative and qualitative analysis of physiotherapy practices in Poland, taking into account factors such as the distribution across all regions of the country, type of practice, physiotherapists' age and education and city size.

Material and methods: The results and analyses presented in this report were based on statistical data taken from the official statistics of the Polish National Chamber of Physiotherapists.

Results: At the end of the 1st quarter of 2020, there were over 11,000 registered individual physiotherapy practices in Poland. The highest concentration of individual physiotherapy practices was in western Poland. The most common demographic profile of physiotherapists who decided to register their practice was that of a young man with a master's degree from a big city.

Conclusions: Future studies should utilize more complete data from other health professions and compare their results with those from other European Union and non-European Union countries.

\section{Key words}

physiotherapist profession, professional practice, statistics 


\section{Introduction}

Probably due to an oversight in the preparation phase of the legislative process, the Act of 25 September 2015 on the Profession of Physiotherapy limited the possibility of conducting business activity only to medical entities. The Act applied to absolutely all new businesses that opened after it came into force (i.e. after 31 May 2016), while the businesses that existed before that date had 2.5 years to adapt. From that moment on, a race against time began to amend the Act of 15 April 2011 on Medical Activity and modify it so that physiotherapists, just like nurses and physicians, could conduct their business activity in the form of physiotherapy practices.

Thanks to the efforts of the representatives of local governments, this goal was achieved. At the end of November, President Andrzej Duda, at an express pace (i.e. two days after the vote by the Senate of the Republic of Poland), signed the Act of 9 November 2018 amending the Act on Medical Activity and some other acts. This introduced regulations that allowed physiotherapists to work in individual and group professional practices, which need to follow the same rules as nurses' practices regarding the conditions for conducting medical activity-an obligation was imposed to register physiotherapists' professional practices in the register of healthcare providers. The body which keeps the register is the Polish Chamber of Physiotherapists (Krajowa Izba Fizjoterapeutów $\mathrm{KIF}$ ). The registration fee for the practice was also set. The Act came into force on 1 April 2019 and set out the obligation to register all activities as practices by 31 October 2019. It now seems advisable to assess how physiotherapy practices are structured in the Republic of Poland.

\section{Aims}

The aim of the study was a quantitative and qualitative analysis of physiotherapy practices in $\mathrm{Po}^{-}$ land, taking into account factors such as distribution among all regions of the country, type of practice, physiotherapists' age and education and city size.

\section{Material and methods}

The statistical data used in this report come from the official statistics of the KIF, which associates all the people who have the right to work as physiotherapists in Poland. Therefore, the data can be treated as official national data in terms of reliability. An overall analysis of physiotherapists' propensity to set up their practice was made based on basic demographic variables, such as gender, age and education level. The regional analysis uses intensity indicators at the voivodship or county level that show the number of physiotherapists running individual practices (of a particular type) from a given territorial unit per 10,000 inhabitants determined according to the Central Statistical Office (Główny Urząd Statystyczny GUS). The frequency of undertaking individual physiotherapy practices was determined by the structure index, expressed as a percentage. The statistical analyses were performed using the STATISTICA 13.0 software.

\section{Results}

Key observations from the study are presented below. Table 1 shows the absolute numbers and percentages of physiotherapy practices in relation to the physiotherapists' age. Table 2 shows the number of individual physiotherapy practices in relation by physiotherapists' level of education. The data presents the situation at the end of the 1st quarter of 2020. 
Table 1. The number of physiotherapy practices in Poland in relation to the physiotherapists' age.

\begin{tabular}{|c|c|c|c|c|}
\hline Age [years] & $\begin{array}{l}\text { Number of } \\
\text { practices [n] }\end{array}$ & $\begin{array}{l}\text { Number of all } \\
\text { physiotherapists in } \\
\text { the given age range } \\
\text { in Poland [n] }\end{array}$ & $\begin{array}{c}\text { Percentage of total } \\
\text { practices [\%] }\end{array}$ & $\begin{array}{c}\text { Percentage of } \\
\text { physiotherapists [\%] }\end{array}$ \\
\hline $20-24$ & 149 & 4340 & 1.3 & 3.4 \\
\hline $25-29$ & 2283 & 15158 & 20.0 & 15.1 \\
\hline $30-34$ & 3572 & 16769 & 31.3 & 21.3 \\
\hline $35-39$ & 2371 & 11620 & 20.7 & 20.4 \\
\hline $40-44$ & 1199 & 5884 & 10.5 & 20.4 \\
\hline $45-49$ & 753 & 4142 & 6.6 & 18.2 \\
\hline $50-54$ & 501 & 3221 & 4.4 & 15.6 \\
\hline $55-59$ & 305 & 2427 & 2.7 & 12.6 \\
\hline $60-64$ & 219 & 2072 & 1.9 & 10.6 \\
\hline Over 65 & 78 & 805 & 0.7 & 9.7 \\
\hline Total & 11430 & 66438 & 100.0 & 17.2 \\
\hline
\end{tabular}

Table 2. The number of physiotherapy practices in Poland by physiotherapists' level of education.

\begin{tabular}{|c|c|c|c|c|}
\hline Age [years] & $\begin{array}{c}\text { Number of } \\
\text { practices [n] }\end{array}$ & $\begin{array}{c}\text { Number of all } \\
\text { physiotherapists in } \\
\text { the given age range } \\
\text { in Poland [n] }\end{array}$ & $\begin{array}{c}\text { Percentage of total } \\
\text { practices [\%] }\end{array}$ & $\begin{array}{c}\text { Percentage of } \\
\text { physiotherapists [\%] }\end{array}$ \\
\hline $\begin{array}{c}\text { Master of } \\
\text { Physiotherapy }\end{array}$ & 9607 & 44145 & 84.1 & 21.8 \\
\hline $\begin{array}{c}\text { Bachelor of } \\
\text { Physiotherapy }\end{array}$ & 1176 & 14935 & 10.3 & 7.9 \\
\hline $\begin{array}{c}\text { Physiotherapy } \\
\text { technician }\end{array}$ & 647 & 8069 & 5.7 & 8.0 \\
\hline Total & 11430 & 67149 & 100.0 & 17.0 \\
\hline
\end{tabular}


The number of physiotherapy practices per 100,000 inhabitants was analysed. The highest density distribution of individual physiotherapy practices was in the western part of Poland, particularly in the Dolnośląskie (19.0) and Wielkopolskie Voivodships (18.0). The lowest density of individual physiotherapy practices was in the Lubelskie (7.5), Podlaskie (9.3) and Świętokrzyskie (9.8) Voivodships. At the county level, the highest number of registered general physiotherapy practices per 100,000 inhabitants was in big cities with county rights (over 250,000 inhabitants), 25.4; in other cities with county rights, the number was about 18; and the lowest was recorded in non-city counties, 9-10 (Map 1).

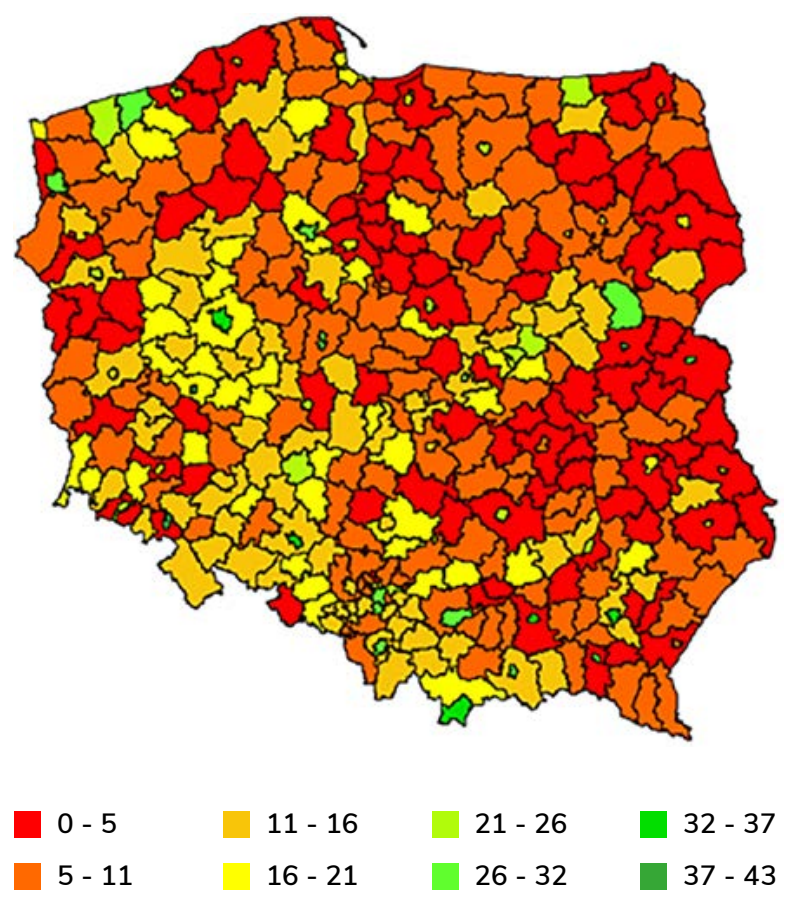

Map 1. The density distribution of individual physiotherapy practices per 100,000 inhabitants in Poland at the county level.
At the end of the 1st quarter of 2020, about 7,000 physiotherapists in Poland had registered their individual, on-call physiotherapy practice. The highest numbers were registered in the Mazowieckie (1392), Wielkopolskie (777) and Malopolskie Voivodships (762) and the lowest numbers in the Podlaskie (88), Lubuskie (101) and Świętokrzyskie Voivodships (136). At the county level, the highest number of registered physiotherapy practices per 100,000 inhabitants was in big cities with county rights (over 250,000 inhabitants), 32.5; in other cities with county rights, the number of practices was about 20; and the lowest number was recorded in non-city counties, about 13-16 (Map 2).

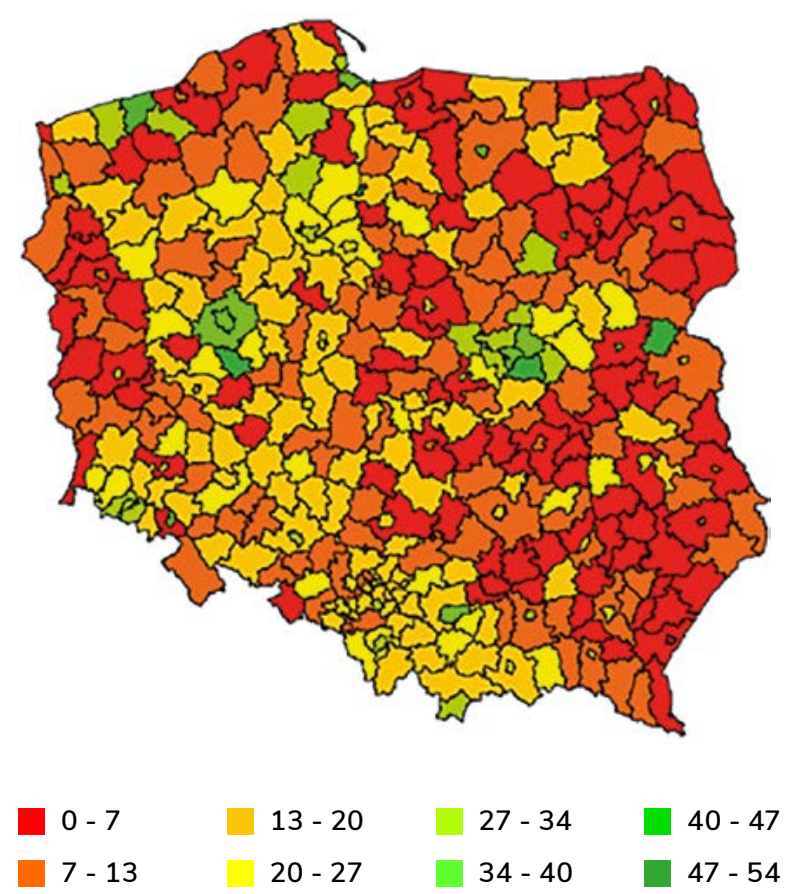

Map 2. Density distribution of on-call individual physiotherapy practices per 100,000 inhabitants in Poland at the county level. 
At the end of the 1st quarter of 2020, there were less than 6,000 registered physiotherapists in Poland. The highest numbers were registered in the Mazowieckie (1772), Kujawsko-Pomorskie (601) and Śląskie Voivodships (1773) and the lowest ones in the Podlaskie (54), Opolskie (64) and Świętokrzyskie Voivodships (65). At the county level, the highest number of registered physiotherapy practices in a treatment institution (per 100,000 inhabitants) was in big cities with county rights (over 250,000 inhabitants), less than 40; this number was much lower in big cities with county rights, nearly 17; and the lowest figure was recorded in small and medium cities with county rights and in non-city counties, 8.4-11.6 (Map 3).

\section{Discussion}

According to our study of the KIF register, over 11,000 individual physiotherapy practices were registered in Poland at the end of the 1st quarter of 2020. A slight majority of them were registered by men (55\%). In absolute terms, the number of male-registered individual physiotherapy practices was nearly 1,000 more than those registered by women $(6,211$ vs 5,219$)$. Considering the total number of male $(17,383)$ and female physiotherapists $(49,774)$ in Poland, we can see that $35.7 \%$ of male and $10.5 \%$ of female physiotherapists decided to register their individual practices. The most common demographic profile of physiotherapists in Poland who decided to start a practice was that of a young man with a master's degree from a big city.

If we look at similar available statistics for the medical and dental professions, there were a total of 4,437 registered physician and dental practices in 2019, of which 3,277 practices were registered in urban areas and 1,160 in rural areas, which are shown in Table 13 [6]. It should be noted that the data refer only to practices providing services under public funds. Interestingly, this legal form does not suit physicians, possibly because of the need to employ additional staff, which can be done much more efficiently by running a medical entity. In our interviews with physiotherapists, we also observed the slow transformation of

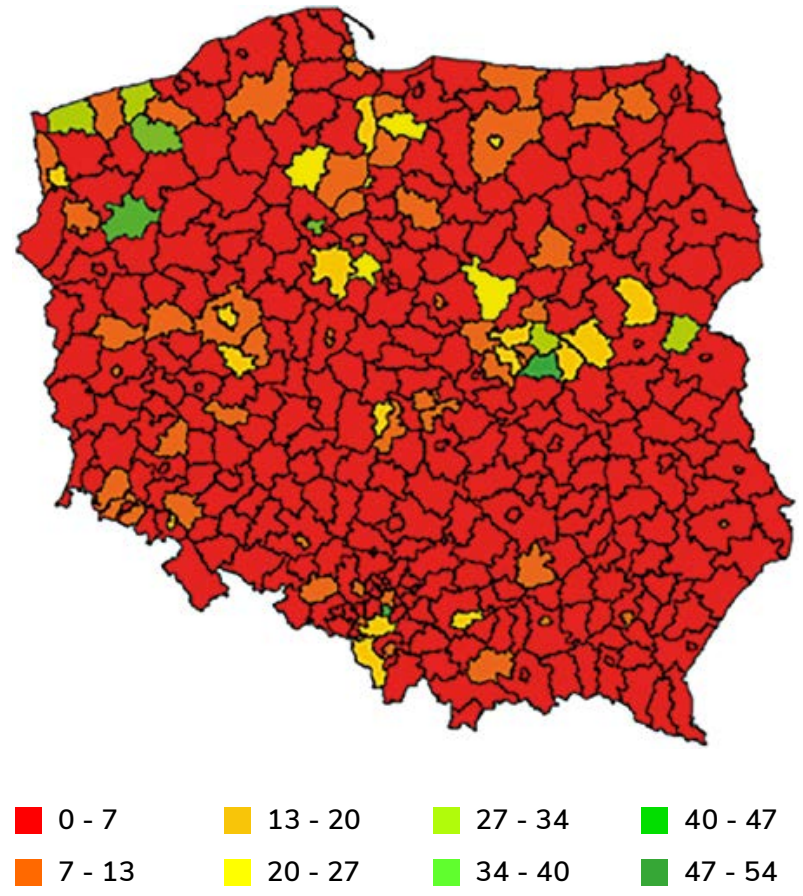

Map 3. The density distribution of individual physiotherapy practices per 100,000 inhabitants in Poland at the county level.

physiotherapy practices into healthcare entities, which seems to be a natural direction in the development of medical companies. The downward trend in the number of medical and dental practices providing services with public funds has continued since 2011. In 2019, there were $8 \%$ fewer of both types of practices compared to 2018 [6].

In 2019, the geographical structure of the distribution of outpatient healthcare facilities was as follows: the largest number of outpatient clinics and practices of physicians and dentists were located in the Mazowieckie Voivodship $(3,400)$, while the smallest number was recorded in the Lubuskie (700), Opolskie (800) and Świętokrzyskie Voivodships (800). Out of a total of 4,400 physician and dentist practices that signed an agreement with the National Health Fund (Narodowy Fundusz Zdrowia - NFZ), the largest number was located in the Wielkopolskie Voivodship (13.3\%) and the smallest in the Małopolskie Voivodship (3.2\%). The distribution of outpatient entities, including outpatient clinics and physi- 
cian practices per 10,000 residents by voivodship, is presented in Chart 60 [6]. The structure of physician practices was similar to the previous year. Individual specialist physician practices dominated (89\%), and the shares of individual (non-specialist) and group physician practices were at similar levels (6.1\% and 5.0\%, respectively). There was also no significant change in the structure of dental practices. Individual dental practices were the most common (58.1\%). This form of outpatient medical care, as in previous years, remains more prevalent in urban areas (37.1\%) than in rural areas (21\%) [6].

Unfortunately, there are no sources or studies on the number, structure or location of professional practices for other health professions (e.g. nurses and midwives). Available data presented by the GUS do not differentiate in detail between physician and dentist practices with a division into privately and publicly provided services. There is a lack of data describing owners of professional practices in terms of gender, age and length of service. In the physiotherapy profession, the highest frequency of establishing individual physiotherapy practices was characteristic of physiotherapists between 30 and 44 years of age, an age group in which the decision was made by slightly more than one in five physiotherapists. Opening an individual practice constitutes a natural next step in this profession. The time to gain the work experience necessary to become an independent practitioner is usually long, ranging from a few to several years, which is not different from other medical professions. Physicians are usually considered independent after completing their specialization, which takes a minimum of 5-6 years after graduation.

The lowest number of physiotherapists who opened their practices was found among those over 55 years of age, where almost every 9th physiotherapist (11.3\%) started a practice. It is not unusual that one has a stable work situation at that age, and the decision to open a practice is quite a significant change, which may result from employers' pressure to change the form of employment to cut labour costs or from physiothe- rapists being forced by changes in legislation and the introduction of physiotherapy practices into the legal order. It will undoubtedly be worth repeating this study because opening a business by people over 55 does not seem like a typical move. Unfortunately, there are no comparable data.

Nationwide, about $17 \%$ of the physiotherapists registered in Poland at the end of the 1st quarter of 2020 were running an individual physiotherapy practice (Table 1). Education was a strong determinant of the tendency to do so. Most physiotherapists in this group had at least a master's degree (about $22 \%$ ), while only $7.9 \%$ had a bachelor's degree $(7.9 \%)$ and $8.0 \%$ a technician degree (Table 2).

Most practices registered by physiotherapists are individual physiotherapy practices, on-call only individual physiotherapy practices and individual physiotherapy practices in a medical institution. At the end of the 1st quarter of 2020 , group physiotherapy practices were registered much less frequently (125) and over 5,300 physiotherapists (8\%) in Poland had registered their individual physiotherapy practice. Of course, the number of registered practices depends on the population of a particular voivodship and the number of physiotherapists working in that region. The highest number of individual physiotherapy practices per 100,000 inhabitants was in western Poland.

About 7,000 physiotherapists in Poland (10.5\%) registered on-call individual physiotherapy practices. The highest frequency of registration was in central-northern Poland. About 6,000 physiotherapists in Poland (9\%) registered their individual physiotherapy practice in a medical institution, with the highest frequency of registration being among physiotherapists in central-northern Poland. It is worth mentioning that 55 out of $380 \mathrm{co}^{-}$ unties in Poland did not register any physiotherapy practices conducted at a medical institution (Map 3).

From a territorial point of view, the highest number of practices are in huge and big cities (over 500,000 inhabitants), a lower number in medium-sized cities and the lowest in non-city co- 
unties. Relatively low numbers of physiotherapy practices are found in eastern and south-eastern Poland and in the Lubuskie Voivodship. In the Podlaskie and Lubuskie Voivodships, this phenomenon is caused by a relatively low number of physiotherapists [4], while in other parts of Poland, the situation results from physiotherapists' decreased willingness to start the above-mentioned practices. To sum up, the different types of individual physiotherapy practices are territorially differentiated. Large numbers of individual physiotherapy practices are found in western and south-western Poland, and physiotherapy practices carried out on call or in a medical institution are most commonly localized in north-central Poland.

This study provides an overview of the quantitative situation concerning all types of physiotherapy practices in Poland. Unfortunately, there are no comparative data from other EU countries. It also seems possible that there is a grey area (informal sector) in this profession. According to the 2020 data from the Central Register and Information on Economic Activity (Centralna Ewidencja i Informacja o Działalności Gospodarczej - CEIDG), there were about 36,000 business entities providing physiotherapy services under the code PKD 86.90a. Many of them are hotels, hospitals or other centres that entered this code accidentally; however, it will be worth verifying the number of physiotherapy service providers without proper licences (no practice or medical entity). Our study is a preliminary attempt to assess the situation of professional practices in physiotherapy and was conducted a few months after the introduction of regulations obliging their establishment. It would certainly be advisable to repeat this type of research and combine its results with those of other studies that focus on issues such as the territorial differentiation of professional activity or the evaluation of employment forms.

\section{Conclusions}

The present research should be continued to analyse the motivation of physiotherapists to start their work practice and other variables that can affect such a decision (geographic, economic and social factors). Future studies should utilize more complete data from other health professions and compare their results with those from other European Union and non-European Union countries. There is a need for an in-depth analysis of the needs of Polish society regarding physiotherapy, which could facilitate or postpone making decisions about establishing a practice in a particular place and time. In addition, there are far fewer physicians' practices than physiotherapists' practices, which may be due to the fact that physicians more often run medical entities.

The full Report „Territorial differentiation of physiotherapy practices in Poland" available at: https://kif.info.pl/wp-content/ uploads/2021/06/Praktyki-fizjoterapeutycznew-Polsce.pdf

\section{References}

1. The Act of 25 th September 2015 on the physiotherapist profession.

2. The Act of 15th April 2011 on medical activity.

3. The Act of 9th November 2018 amending the Act on medical activity and some other acts.

4. Woźnica D, Śmigielski W, Koper A, Krawczyk M, Niewiadomski T, Adamkiewicz P et al. Territorial differentiation in the physiotherapy profession in Poland. Physiotherapy Review. 2021; 25 (1): 52-61. doi:10.5114/phr.2021.104603.

5. The Resolution No. 427/I of the Polish Chamber of Physiotherapists of 24th October 2019 on the position of the Polish Chamber of Physiotherapists concerning practicing physiotherapy profession within a medical entity.

6. Statistics Poland and Statistical Office in Kraków. Health and health care in 2019, Warsaw and Cracow 2020, ISSN 2084-0470, Available at: 10/1/zdrowie_i_ochrona_zdrowia_2019.pdf 